\title{
HUBUNGAN SELF-PRESENTATION DENGAN KEPUASAN TUBUH REMAJA PADA SMP X
}

\author{
Christine Hadinata ${ }^{1}$, Riana Sahrani ${ }^{2}$, Debora Basaria ${ }^{3}$ \\ ${ }^{1}$ Program Studi Magister Psikologi Profesi, Universitas Tarumanagara \\ Email: christine.717201018@stu.untar.ac.id \\ ${ }^{2}$ Fakultas Psikologi, Universitas Tarumanagara \\ Email: rianas@fpsi.untar.ac.id \\ ${ }^{3}$ Fakultas Psikologi, Universitas Tarumanagara \\ Email:deborab@fpsi.untar.ac.id
}

Masuk : 26-09-2020, revisi: 26-10-2020, diterima untuk diterbitkan : 31-10-2020

\begin{abstract}
Adolescents who go through puberty will experience various change, adolescents will experience physical changes. The physical changes experienced will affect body satisfaction which is part of adolescent self-identity. In addition, social media also contributes to adolescent body satisfaction. In social media, adolescents can see various exposures to the ideal body shape of artists, friends, or other people which in turn make adolescents insecure and can reduce body satisfaction. But on the other hand, adolescents want to show their existence and want to be recognized by others. The existence of social media makes it easier for adolescents to show their existence through photos uploaded on social media. Photos uploaded on social media can be in the form of selfie which are part of self-presentation. Adolescents pay attention to physical appearance and want to appear as attractive as possible, so that teenagers will present their ideal self on social media. The intensity of uploading photos on social media is related to the level of body satisfaction. Adolescents who frequently upload photos on social media have lower body satisfaction. This study aims to see the relationship between self-presentation and adolescent body satisfaction in SMP X. The subjects of this study were adolescents or junior high school students, totaling 167 participants. The research data was taken using a questionnaire, the results of the study found that there was no relationship between selfie and body satisfaction. However, there is a relationship between the dimensions of self-relationship that attempt to act with body satisfaction in the facial area
\end{abstract}

Keywords: self-presentation, body satisfaction, adolescent

\begin{abstract}
ABSTRAK
Pada masa pubertas remaja akan mengalami beberapa perubahan salah satunya perubahan fisik. Perubahan fisik tersebut dapat membentuk tingkat kepuasan tubuh remaja yang menjadi suatu bagian dari identitas diri. Selain itu, adanya media sosial berkontribusi pada kepuasan tubuh remaja. Pada media sosial, remaja dapat melihat berbagai paparan bentuk tubuh ideal artis, teman, atau orang lain yang pada akhirnya membuat remaja tidak percaya diri dan dapat menyebabkan rendahnya kepuasan tubuh. Namun, di sisi lain remaja ingin menunjukkan eksistensi dirinya dan ingin diakui oleh orang lain. Adanya media sosial mempermudah remaja untuk menunjukkan eksistensi melalui foto yang di unggah di media sosial. Salah satu foto yang diunggah dapat berupa selfie yang merupakan salah satu bentuk dari self-presentation. Remaja sangat memperhatikan penampilan fisik dan ingin tampil semenarik mungkin, sehingga remaja akan menampilkan diri ideal mereka di media sosial. Intensitas mengunggah foto di media sosial berhubungan dengan tingkat kepuasan tubuh. Semakin sering remaja mengunggah foto di media sosial, semakin rendah kepuasan tubuhnya. Pada penelitian ini bertujuan untuk mengetahui hubungan self-presentation dengan kepuasan tubuh yang dimiliki remaja pada SMP X. Subyek penelitian ini merupakan remaja atau siswa-siswi SMP yang berjumlah 167 partisipan. Data penelitian ini diambil menggunakan kuesioner, pada hasil penelitian ditemukan tidak terdapat hubungan antara memfoto diri sendiri (selfie) dengan kepuasan tubuh. Meskipun demikian terdapat hubungan self-presentation dimensi attempt to act dengan kepuasan tubuh area wajah.
\end{abstract}

Kata Kunci: self-presentation, body satisfaction, remaja

\section{PENDAHULUAN}

Remaja yang sedang berada pada masa pubertas seringkali melihat bentuk tubuh sebagai salah satu hal yang berperan penting dalam menemukan identitas diri mereka. Namun diketahui tidak sedikit remaja yang memandang tubuh mereka secara negatif, dimana remaja melakukan diet 
ekstrim karena tidak percaya diri dengan bentuk tubuhnya (Aristantya, 2019). Pada media sosial, remaja juga dapat melihat bentuk paparan tubuh yang ideal dari sejumlah artis, selebgram, teman, maupun orang lain. Sehingga membuat remaja melakukan perbandingan dengan bentuk tubuh mereka. Oleh karena itu, mengakses media sosial dianggap memiliki pengaruh terhadap kepuasan tubuh yang rendah (McLean, Paxton, Wertheim, \& Masters, 2015).

Kepuasan tubuh (body satisfaction) merupakan bagaimana individu menilai bentuk tubuh secara keseluruhan dari kepala sampai ujung kaki serta individu puas dengan bentuk tubuh yang dimiliki (Dohnt, \& Tiggemann, 2006). Berdasarkan Rieke, Fowler, Chang, dan Velikova (2016) terdapat empat faktor yang dapat mempengaruhi kepuasan seseorang akan tubuhnya yaitu: (a) faktor personal, seperti gambaran ideal mengenai tubuhnya, dan kepercayaan diri; (b) faktor sosial, seperti media, teman, dan keluarga. Sejalan dengan itu Lawler dan Nixon (2011) menyebutkan kepuasan seseorang akan tubuhnya dipengaruhi oleh: (a) budaya mengenai standar keindahan tubuh yang diperkuat faktor sosial, (b) media, (c) teman sebaya, (d) orangtua, (e) berat badan, (f) penilaian penampilan dari teman sebaya, dan (g) internalisasi. Pada penelitian Martjin, Vanderlinden, Roefs, Huijding, dan Jansen (2010) angka ketidakpuasan tubuh sebanyak 80,8\% pada perempuan dan $54,8 \%$ pada laki-laki, sehingga seringkali perempuan memiliki keinginan untuk mengubah bentuk atau ukuran tubuh mereka (Lawler, \& Nixon, 2011). Berkebalikan dari penelitian sebelumnya, pada penelitian ini ditemukan laki-laki memiliki tingkat kepuasan tubuh yang rendah dibandingkan perempuan (McCabe et al., 2011).

Hampir seluruh remaja di era digital saat ini mengenal internet yang umumnya digunakan untuk menunjang aktivitas dan mengeksplorasi diri mereka. Pada masa pencarian identitas diri seringkali remaja mengeksplorasi diri mereka dengan cara memposting di media sosial dengan harapan postingan tersebut mendapat likes dan komentar positif (menurut Weiser dalam Charoensukmongkol, 2016). Seorang remaja yang menggunakan media sosial sebagai media untuk melakukan presentasi diri (self-presentation) agar memperoleh pengakuan (Goffman dalam Worchel, Cooper, Goethals, \& Olson, 2000). Sehingga remaja menjadi gemar untuk memfoto diri beserta memposting semua aktivitas ke media sosial dalam membentuk identitas mereka (Ramadhan, Aminulloh, \& Yasak, 2017). Sejalan dengan hal tersebut postingan di media sosial digunakan untuk membuat identias online (Merunkova \& Slerka, 2019).

Menurut Goffman self-presentation terdiri dari dua dimensi, yang pertama ability to act merupakan kemampuan individu untuk dapat tampil percaya diri didepan orang lain. Kedua, attempt to act merupakan individu akan berperilaku dengan tujuan menyenangkan hati orang lain. Salah satu kegiatan yang dilakukan remaja adalah selfie. Remaja mengidentifikasi selfie sebagai tindakan mengekspresikan dan presentasi diri atau self-presentation (Lobo, \& Gowda, 2016). Selfie dapat meningkatkan self-presentation dengan memposting hal yang diinginkan secara sosial (Lobo, \& Gowda, 2016). Remaja mengunggah foto selfie di media sosial agar dapat dilihat banyak orang serta mendapat timbal balik (Albury, 2015). Tanggapan umpan balik mengenai postingan selfie seperti jumlah likes yang diterima serta komentar merepresentasikan seberapa besar penerimaan sosial (McLean, Jarman, \& Rodgers, 2019). Sehingga, apabila mendapat jumlah likes yang tidak sesuai yang diharapkan remaja menjadi kurang percaya diri. Sejalan dengan itu terdapat penelitian lain yang mengatakan bahwa selfie merupakan indikator rendahnya self-esteem, ketergantungan sosial dan perilaku mencari perhatian (Lobo, \& Gowda, 2016). Sejalan dengan hal tersebut, terdapat penelitian yang dilakukan Meier dan Gray (2014) mengatakan remaja perempuan yang lebih exposure di Facebook seperti mengunggah foto sendiri memiliki ketidakpuasan tubuh yang lebih besar daripada individu yang jarang mengakses foto di Facebook. Selain itu melakukan perbandingan dengan orang lain (Myers, Ridolfi, 
Crowther, \& Ciesla, 2012). Melalui media sosial perempuan cenderung menampilkan dirinya yang ideal melalui foto. Selain itu, sangat mungkin perempuan melakukan perbandingan dengan pengguna akun di media sosial lain yang dipercayai lebih menarik dari mereka sendiri (Myers et al., 2012).

Kesimpuan dari hasil beberapa penelitian diatas adalah remaja yang sering menghabiskan waktu di media sosial memiliki hubungan dengan kekhawatiran akan tubuhnya. Begitu juga sebaliknya, perempuan yang jarang menghabiskan waktu pada media sosial berkontribusi lebih sedikit akan kekhawatiran tubuhnya (McLean et al., 2015). Akibatnya, melalui media sosial remaja lebih terfokus pada penampilan, penampilan yang ideal sehingga dapat menyebabkan ketidakpuasan tubuh. Remaja yang memiliki mengalami ketidakpuasan tubuh seperti melakukan pengecekkan, melakukan penilaian akan bentuk tubuh (McLean et al., 2015). Namun, adanya perbedaan generasi remaja memiliki hasil yang berbeda pada tingkat kepuasan tubuh. Sehingga peneliti ingin melihat hubungan self-presentation dengan kepuasan tubuh remaja. Apakah terdapat hubungan self-presentation dengan kepuasan tubuh remaja pada SMP X?

\section{METODE PENELITIAN}

Karakteristik subyek penelitian merupakan remaja yang berusia 12-16 tahun yang pernah melakukan kegiatan selfie minimal 1x. Selanjutnya remaja pernah memposting foto kegiatan selfie di media sosial minimal 1x. Tidak ada batasan suku bangsa, ras, agama, jenis kelamin, maupun tempat tinggal. Pada gambaran subyek dari total 167 subyek, yang berjenis kelamin laki-laki terdapat 66 orang dan subyek yang berjenis kelamin perempuan terdapat 101 orang dengan pendidikan terakhir SD. Teknik yang digunakan dalam pengambilan data merupakan nonprobability sampling, yaitu purposive sampling dan menggunakan metode penelitian kuantitatif.

Penelitian ini menggunakan alat ukur Self-Presentation berisi 18 butir dengan pernyataan dengan pilihan jawaban B (benar) dan S (salah). Peneliti menggunakan alat ukur yang diadaptasi oleh Winda Andrian Jusuf (2015) dengan dua dimensi ability to act dan attempt to act. Pada dimensi ability to act terdiri dari 5 pernyataan negatif $(1,5,11,15,17)$, dan 5 pernyataan positif $(2,4,13$, 14, 18). Pada dimensi attempt to act terdiri dari 2 pernyataan negatif (9, dan 16), dan 6 pernyataan positif $(3,6,7,8,10,12)$. Pada butir pernyataan positif diberi nilai dengan cara $\mathrm{B}=1$ dan $S=0$. Sebaliknya, pada butir pernyataan negatif diberi nilai dengan cara $B=0$ dan $S=1$.Teori yang digunakan yaitu teori Goffman dengan adaptasi dari alat ukur Self-Presentation Scales yang dibuat oleh Ackerman. Individu yang terlibat dalam perilaku yang bertujuan merefleksikan dirinya, maka individu sedang melakukan self-presentation.

Selanjutnya menggunakan alat ukur Body Satisfaction Scale (BSS) yang merupakan adaptasi dari A. Rusli dan Ainul F. Lismayati (2018) berisi 16 butir item bagian tubuh dengan mengukur 3 area yaitu area bentuk, area wajah, dan area atas. Adaptasi alat ukur bersumber dari Body Satisfaction Scale (BSS) yang dikembangkan oleh Slade pada tahun 1990. Teori yang digunakan pada alat ukur ini yaitu body-cathexis. Body-cathexis merupakan tingkat perasaan puas atau tidak puas berbagai bagian dan perubahan tubuh (Song \& Ashdown, 2013). Alat ukur ini menggunakan skala linkert, terdiri dari $1=$ Sangat Tidak Puas, $2=$ Tidak Puas, $3=$ Cenderung Tidak Puas, 4= Netal, 5=Cukup Puas, 6=Puas, 7=Sangat Puas.

Pada alat ukur Self-Presentation Scale dimensi ability to act terdiri dari 10 butir setelah dilakukan uji reliabilitas terjadi pembuangan butir alat ukur sehingga menjadi 8 butir dengan internal consistency reliability 0.671. Pada dimensi attempt to act terdiri dari 8 butir dilakukan uji reliabilitas terjadi pembuangan butir alat ukur sehingga menjadi 6 butir internal consistency 
reliability 0.629. Pada alat ukur Body Satisfaction Scale, uji reliabilitas dilakukan pada 3 dimensi. Sehingga didapatkan hasil pada dimensi area wajah consistency reliability 0.698 , pada dimensi area atas internal consistency reliability 0.640 , pada dimensi area bentuk internal consistency reliability 0.852 .

\section{HASIL DAN PEMBAHASAN}

Pada gambaran data terkait frekuensi remaja di SMP X melakukan foto selfie dan diupload. Sebanyak 2 subjek (1.2\%) menjawab lebih dari 5 kali sehari melakukan foto selfie dan diupload. Sebanyak 22 subjek (13.2\%) menjawab 1-5 kali sehari melakukan foto selfie dan diupload. Sebanyak 15 subjek (9\%) menjawab 1-4 kali sehari melakukan foto selfie dan diupload. Sebanyak 44 subjek (26.3\%) menjawab 1-5 kali seminggu melakukan foto selfie dan diupload. Sebanyak 42 subjek (25.1\%) menjawab 1-2 kali sebulan melakukan foto selfie dan diupload. Sebanyak 22 subjek (13.2\%) menjawab 1-2 kali setahun melakukan foto selfie dan diupload. Sebanyak 20 subjek (12\%) menjawab lainnya. Sehingga dapat disimpulkan data paling banyak yaitu subyek yang foto selfie dan diupload sebanyak 1-5 kali seminggu berjumlah 44 orang (26.3\%). Subyek yang paling sedikit adalah subyek yang foto selfie dan diupload lebih dari 5 kali sehari sebanyak 2 orang (1.2\%).

Pada gambaran data terkait intensitas subjek di SMP X yang melakukan edit foto sebelum diupload. Sebanyak 47 subjek (28.1\%) menjawab tidak pernah melakukan edit foto sebelum diupload. Sebanyak 66 subjek (39.5\%) menjawab jarang melakukan edit foto sebelum diupload. Sebanyak 34 subjek (20.4\%) menjawab kadang-kadang melakukan edit foto sebelum diupload. Sebanyak 9 subjek (5.4\%) menjawab sering melakukan edit foto sebelum diupload. Sebanyak 11 subjek (6.6\%) menjawab selalu melakukan edit foto sebelum diupload. Sehingga dapat disimpulkan jawaban terbanyak subyek menjawab jarang edit foto sebelum diupload berjumlah 66 orang (39.5\%), sedangkan subyek yang menjawab paling sedikit menjawab sering berjumlah 9 orang $(5.4 \%)$.

Pada gambaran data terkait perasaan subjek di SMP X mendapatkan sedikit likes pada foto yang diupload. Sebanyak 8 subjek (4.8\%) merasa sedih saat mendapatkan sedikit likes. Sebanyak 20 subjek (12\%) mencoba berpikir positif saat mendapatkan sedikit likes. Sebanyak 126 subjek (75.4\%) tidak mempedulikan hal tersebut saat mendapatkan sedikit likes. Sebanyak 3 subjek $(1.8 \%)$ biasa saja saat mendapatkan sedikit likes. Sebanyak 10 subjek $(6 \%)$ menjawab lainnya. Sehingga dapat disimpulkan paling banyak subyek menjawab tidak mempedulikan hal tersebut yang berjumlah 126 orang $(75.4 \%)$, sedangkan yang paling sedikit subyek menjawab biasa saja yang berjumlah 3 orang $(1.8 \%)$.

Pada gambaran data kepuasan tubuh menggunakan skala 1-7 dengan mean hipotetik (median) alat ukur yaitu 4. Berdasarkan data penelitian diperoleh nilai mean empirik dimensi area bentuk 4.9078, dimensi area wajah 4.8473 dimensi area atas sebesar 5.1772, dan kepuasan tubuh secara keseluruhan sebesar 4.9774 sehingga dapat diasumsikan subyek memiliki kepuasan tubuh yang tinggi. Gambaran data self-presentation nilai mean empirik dimensi ability to act sebesar 0.4049 dan dimensi attempt to act sebesar 0.5918. Nilai mean empirik dimensi self-presentation secara keseluruhan sebesar 0.4984. Sehingga dapat disimpulkan subyek memiliki self-presentation cukup tinggi. Dilakukan uji normalitas variabel Body Satisfaction Scale, Kolmogorov Smirnov $\mathrm{Z}=0.720, \mathrm{p}=0.678>0.05$ data terdistribusi normal. Pada variabel self-presentation, Nilai Kolmogorov Smirnov $\mathrm{Z}=0.895, \mathrm{p}=0.400>0.05$ data terdistribusi normal. Analisis data menggunakan uji korelasi Pearson. Pada hasil analisis data tersebut ditemukan nilai $r(167)=-0.76$, $\mathrm{p}=0.330>0.05$ sehingga tidak ada perbedaan antara self-presentation dengan kepuasan tubuh. 
Peneliti melakukan analisis data kepuasan tubuh dengan variabel kontrol, untuk melihat apakah kepuasan tubuh dipengaruhi oleh variabel lain. Peneliti ingin melihat apakah terdapat hubungan kepuasan tubuh ditinjau dari intensitas mengedit foto sebelum diupload. Rata-rata kepuasan tubuh subyek yang tidak pernah edit foto adalah $5.0132(\mathrm{SD}=0.64371)$, rata-rata kepuasan tubuh subyek yang jarang edit foto adalah 5.0025 ( $\mathrm{SD}=0.77137)$, rata-rata kepuasan tubuh subyek yang kadang-kadang edit foto adalah 4.8474 ( $\mathrm{SD}=0.78752)$, rata-rata kepuasan tubuh subyek yang sering edit foto adalah $5.2877(\mathrm{SD}=0.68042)$, rata-rata kepuasan tubuh subyek yang selalu edit foto adalah $4.8222(\mathrm{SD}=1.06727)$. Analisis data dilakukan menggunakan One Way ANOVA Between Subject Design. Kemudian peneliti melakukan uji homogenitas kelompok menggunakan Lavene Statistic sebesar 1.144 dengan $\mathrm{p}=0.338>0.05$, yang berarti varians antar kelompok intensitas edit foto homogen. Pada hasil analisis data diperoleh nilai ANOVA $\mathrm{F}(4.162)=0.785, \mathrm{p}=0.537>0.05 \mathrm{H} 0$ diterima. Sehingga, dapat disimpulkan tidak terdapat perbedaan kepuasan tubuh berdasarkan intensitas mengedit foto. Peneliti ingin melihat apakah terdapat hubungan kepuasan tubuh berdasarkan sedikit likes. Peneliti melakukan uji homogenitas menggunakan Lavene Statistic sebesar 2.193, dengan $\mathrm{p}=0.072>0.05$, berarti variansi antar kelompok sedikit likes homogen. Rata-rata kepuasan tubuh subyek yang merasa sedih saat mendapat sedikit likes adalah 5.0181 ( $\mathrm{SD}=0.49370)$, rata-rata kepuasan tubuh subyek yang mencoba berpikir positif saat mendapat sedikit likes adalah 5.2750 ( $\mathrm{SD}=0.54179$ ), rata-rata kepuasan tubuh subyek yang tidak mempedulikan hal tersebut saat mendapat sedikit likes adalah 4.9151 ( $\mathrm{SD}=0.79128$ ), rata-rata kepuasan tubuh subyek yang biasa saja saat mendapat sedikit likes adalah $5.7556(\mathrm{SD}=0.31759)$, rata-rata kepuasan tubuh subyek yang menjawab lainnya saat mendapat sedikit likes adalah 4.9022 ( $\mathrm{SD}=0.76069$ ). Pada hasil analisis uji perbedaan one way ANOVA between subject design diperoleh nilai $\mathrm{F}(4.162)=1.846, \mathrm{p}=0.122>0.05$ sehingga dapat disimpulkan tidak terdapat perbedaan kepuasan tubuh berdasarkan sedikit likes.

Peneliti melakukan analisis data self-presentation ditinjau dari jenis kelamin menggunakan uji perbedaan Independent Samples t-Test. Pada hasil analisi data tersebut ditemukan nilai $\mathrm{p}=0.019<0.05$, nilai mean pada jenis kelamin laki-laki sebesar 0.5350 , nilai mean pada jenis kelamin perempuan sebesar 0.4744. Sehinga self-presentation pada laki-laki lebih besar dari perempuan. Selanjutnya melakukan analisa data self-presentation berdasarkan intensitas edit foto, kemudian melakukan uji homogenitas menggunakan Lavene Statistic sebesar 1.920 dengan $\mathrm{p}=0.110>0.05$. Pada saat melakukan analisa kepuasan tubuh berdasarkan usia. Peneliti melakukan uji homogenitas Lavene Statistic sebesar 2.798, $\mathrm{p}=0.028<0.05$. Kemudian peneliti melakukan analisis uji perbedaan Kruskal Wallis nilai $\mathrm{p}=0.418>0.05$. Berdasarkan data tersebut dapat disimpulkan tidak ada perbedaan kepuasan tubuh berdasarkan usia. Pada proses melakukan analisa kepuasan tubuh ditinjau dari perasaan setelah melakukan selfie. Peneliti melakukan uji homogenitas menggunakan Lavene Statistic sebesar 1.098, dengan $\mathrm{p}=0.364>0.05$, Pada hasil analisis uji perbedaan one way ANOVA between subject design diperoleh nilai $\mathrm{F}(5.161)=4.572$, $\mathrm{p}=0.001<0.05$ sehingga diperoleh hasil signifikan. Selanjutnya peneliti melakukan uji Post Hoc menggunakan Bonferroni hasil analisis data tersebut ditemukan terdapat perbedaan pada remaja yang bangga dan kurang yakin dengan penampilan setelah melakukan selfie.

Peneliti melakukan analisis data variabel self-presentation dimensi ability to act dengan kepuasan tubuh. Peneliti melakukan uji hubungan variabel self-presentation dimensi ability to act dengan kepuasan tubuh area bentuk. Analisis data menggunakan uji korelasi Pearson. Pada hasil analisis data tersebut ditemukan nilai $\mathrm{r}(167)=0.041, \mathrm{p}=0.599>0.05$ dengan demikian maka dapat disimpulkan tidak ada hubungan antara self-presentation dimensi ability to act dengan kepuasan tubuh area bentuk. Peneliti melakukan uji hubungan variabel self-presentation dimensi 
ability to act dengan kepuasan tubuh area wajah. Analisis data menggunakan uji korelasi Pearson. Pada hasil analisis data tersebut ditemukan nilai $\mathrm{r}(167)=0.137, \mathrm{p}=0.077>0.05$ dengan demikian maka dapat disimpulkan tidak ada hubungan antara self-presentation dimensi ability to act dengan kepuasan tubuh area wajah. Peneliti melakukan uji hubungan variabel selfpresentation dimensi ability to act dengan body satisfaction area atas. Analisis data menggunakan uji korelasi Pearson. Pada hasil analisis data tersebut ditemukan nilai r (167) =0.007, $\mathrm{p}=0.933>0.05$ dengan demikian maka dapat disimpulkan tidak ada hubungan antara selfpresentation dimensi ability to act dengan kepuasan tubuh area atas.

Peneliti melakukan analisis data variabel self-presentation dimensi attempt to act dengan kepuasan tubuh. Peneliti melakukan uji hubungan variabel self-presentation dimensi attempt to act dengan kepuasan tubuh area bentuk. Analisis data menggunakan uji korelasi Pearson. Pada hasil analisis data tersebut ditemukan nilai $\mathrm{r}(167)=-0.082, \mathrm{p}=0.290>0.05$ dengan demikian maka dapat disimpulkan tidak ada hubungan antara self-presentation dimensi attempt to act dengan kepuasan tubuh area bentuk. Peneliti melakukan uji hubungan variabel self-presentation dimensi attempt to act dengan kepuasan tubuh area wajah. Analisis data menggunakan uji korelasi Pearson. Pada hasil analisis data tersebut ditemukan nilai $r(167)=-0.221$, $\mathrm{p}=0.004<0.05$ dengan demikian maka dapat disimpulkan terdapat hubungan antara selfpresentation dimensi attempt to act dengan kepuasan tubuh area wajah. Sehingga semakin tinggi seseorang melakukan self-presentation agar disukai orang lain maka semakin rendah kepuasan tubuh pada area wajah. Peneliti melakukan uji hubungan variabel self-presentation dimensi attempt to act dengan kepuasan tubuh area atas. Analisis data menggunakan uji korelasi Pearson. Pada hasil analisis data tersebut ditemukan nilai $\mathrm{r}(167)=-0.137, \mathrm{p}=0.077>0.05$ dengan demikian maka dapat disimpulkan tidak ada hubungan antara self-presentation dimensi attempt to act dengan kepuasan tubuh area atas.

Berdasarkan hasil uji korelasi mengenai hubungan self-presentation dengan kepuasan tubuh remaja pada SMP X didapatkan $r(167)=-0.76, p=0.330>0.05$. Sehingga disimpulkan $p$ lebih besar dari 0.05 hal ini menjelaskan tidak terdapat hubungan hubungan self-presentation dengan kepuasan tubuh remaja pada SMP X.

Berdasarkan hasil analisis data utama bahwa tidak terdapat hubungan self-presentation dengan kepuasan tubuh remaja. Hal ini dapat disebabkan oleh beberapa faktor, pertama jumlah subyek yang sedikit berjumlah 167 subyek, sehingga belum dapat mengeneralisasi pada populasi yang lebih besar. Kedua, penelitian ini merupakan studi kasus pada satu sekolah saja. Berdasarkan pada gambaran subyek mengenai intensitas edit foto dengan jawaban terbanyak 39,5\% subyek jarang melakukan edit foto sebelum diupload di media sosial. Subyek penelitian ini, merupakan remaja yang memiliki kepercayaan diri yang baik. Hal ini dapat disebabkan karena setiap sekolah memiliki iklim dan budaya sekolah berbeda, budaya sekolah yang menerapkan kebiasaan positif dapat menciptakan siswa bersikap lebih positif seperti lebih diterima dan dihargai (Zahroh, 2015). Iklim dan kebiasaan yang diterapkan pada setiap sekolah berbeda sehingga dapat menciptakan hasil yang berbeda juga.

Ketiga pada penelitian ini merupakan remaja muda berusia 12-16 tahun, siswa SMP yang merupakan subyek penelitian. Sedangkan, penelitian sebelumnya merupakan siswa SMA, mahasiswa, dan dewasa. Tentunya masing-masing usia memiliki tahap perkembangan yang berbeda-beda baik siswa SMP, SMA, mahasiswa maupun dewasa. Pada penelitian yang dilakukan Ardari (2016) mengatakan remaja muda memiliki tingkat kepercayaan yang lebih tinggi daripada remaja tengah, akhir, maupun yang sudah dewasa. 
Keempat, alat ukur yang digunakan merupakan alat ukur yang menggambarkan self-presentation, bukan alat ukur khusus mengukur selfie. Meskipun demikian berdasarkan analisa data bahwa terdapat hubungan negatif antara self-presentation dimensi attempt to act dengan kepuasan tubuh area wajah. Hal ini sejalan dengan pernyataan bahwa individu berusaha menampilkan diri agar mendapat kesan yang baik dari orang lain (Koyuncu, Tok, Canpolat, \& Catikkas, 2010). Penggunaan media sosial yang aktif seperti selfie berkontribusi pada kepuasan tubuh rendah karena meningkatkan fokus pada penampilan (Tiggermann, \& Slater dalam McLean et al., 2015). Umumnya selfie yang diupload di media sosial menampilkan pada area wajah, pentingnya area wajah agar terlihat lebih menarik merupakan salah satu standar kecantikan. Hal ini dapat terlihat pada penelitian Renfrew Center Foundation (2014) umumnya bila seseorang melakukan edit foto pada bagian wajah seperti menghilangkan noda, mengubah warna kulit.

Kelima, pada hasil analisa data dikatakan bahwa tidak terdapat perbedaan kepuasan tubuh berdasarkan intensitas melakukan edit foto. Hal ini menunjukkan bahwa remaja percaya diri dengan tubuh yang dimiliki. Remaja yang percaya diri umumnya tidak mudah tertekan di media sosial. Hal ini dapat terlihat pada analisis data bahwa tidak terdapat perbedaan body satisfaction berdasarkan sedikit likes. Dapat disimpulkan remaja tidak mudah tertekan saat mendapat sedikit likes, bahkan berdasarkan perasaan subyek yang mendapat sedikit likes paling banyak subyek menjawab tidak mempedulikan hal tersebut (75.4\%). Pada penelitian Pokrajac-Bulian dan AmbrosiRandic remaja yang tidak mudah tertekan akibat sosial media, tidak berhubungan dengan kepuasan tubuh (Mostafa, Eshak, Seedhom, \& Ghazawy, 2018).

Keenam, selanjutnya dapat disebabkan remaja menggunakan media sosial untuk mencari popularitas. Pada gambaran data self-presentation dengan nilai mean empirik dimensi ability to act sebesar 0.4049 dan nilai mean empirik dimensi attempt to act sebesar 0.5918. Pada data tersebut menunjukkan cukup tinggi nilai self-presentation. Sehingga tidak diherankan berdasarkan gambaran frekuensi selfie yang diupload jawaban terbanyak adalah 1-5 kali seminggu (26.3\%) hal ini menunjukkan remaja aktif di media sosial.

Berdasarkan hasil analisa data terdapat perbedaan self-presentation berdasarkan jenis kelamin, remaja laki-laki melakukan self-presentation lebih tinggi daripada perempuan. Hal ini disebabkan remaja laki-laki sering menggunakan media sosial untuk mencari teman baru dan lebih terlibat dalam aktivitas yang berbeda pada jaringan sosial yang berbeda (mBarker dalam Herring, \& Kapidzic, 2015). Selain itu umumnya remaja laki-laki membagikan konten di media sosial untuk mempromosikan diri sendiri (menurut Peluchette, \& Karl dalam Herring, \& Kapidzic, 2015). Meskipun remaja perempuan lebih memilih foto dimana terlihat lebih menarik seperti menggoda, namun remaja laki-laki lebih variatif terhadap konten yang diupload di media sosial seperti dominan, ideal, dan menggoda (Manago, Graham, Greenfield, \& Salimkhan, 2008).

Terdapat penelitian lain dimana melalui foto yang diunggah merupakan bentuk mencurahkan perasaan dan sebagai hiburan. Melalui foto dan status yang diunggah menjadi kepuasan tersendiri bagi remaja dapat mengkespresikan diri di media sosial, selain itu eksistensi remaja yang ingin karyanya dikenal banyak orang dan menjadi terkenal (Estiyani, 2018). Seperti saat ini, tidak hanya selfie saja tapi aplikasi yang sangat tenar seperti Tik Tok dimana remaja memperoleh manfaat dari penggunaan Tik Tok seperti dapat menunjukkan eksistensi, meningkatkan kreativitas sehingga remaja dapat keluar dari zona nyaman, lebih percaya diri, tidak peduli dengan perkataan orang lain, dan dapat menghilangkan stres (Fauziah, 2019). Memposting foto selfie merupakan bentuk dari kepercayaan diri yang tinggi (Seiter dalam Lobo dan Gowda, 2016). 
Hal ini selaras pada penelitian Ardari yang mengatakan bahwa kepercayaan diri remaja tidak mempengaruhi penggunaan media sosial karena sikap dan cara berpikir remaja yang lebih positif dan percaya diri pada kemampuan diri sendiri dalam menggunakan media sosial (Baker \& White dalam Ardari, 2016). Memposting foto selfie dapat mengontrol gambaran ideal seseorang, sehingga menjadi realistis dan meningkatkan harga diri (Frost \& McKelvie, 2004).

Menurut Smith dalam Fitriawati, \& Retnasary (2018) terdapat ciri-ciri individu yang memiliki eksistensi diri yaitu: (a) memiliki kepercayaan diri untuk melihat sisi positif dari suatu peristiwa, (b) kesadaran akan keunikan diri sehingga tidak membanding-bandingkan dengan orang lain, (c) tetap tenang meskipun dilanda masalah.

\section{KESIMPULAN DAN SARAN}

Berdasarkan penjabaran tersebut apat disimpulkan bahwa remaja di SMP X menggunakan media sosial dengan fokus utama yaitu populer dan dapat menunjukkan karyanya pada orang lain. Mencari popularitas merupakan salah satu remaja melakukan eksistensi diri.

Terdapat beberapa saran teoretis yang dapat diberikan yaitu pada bidang psikologi klinis dan perkembangan remaja hasil penelitian ini dapat terlihat bagaimana perkembangan remaja mencari identitas diri pada era digital ini. Selain itu, dapat memperbanyak jumlah penelitian mengenai self-presentation dengan body satisfaction karena masih sedikit jumlah penelitiannya terutama di Indonesia. Saran untuk peneliti selanjutnya mempertimbangkan bahwa selfpresentation dapat berupa tulisan, video, maupun audio, sehingga bisa ditambahkan pilihan pada data kontrol bagaimana remaja melakukan self-presentation di media sosial. Selain itu diharapkan peneliti selanjutnya juga mempertimbangkan jumlah subyek agar dapat digeneralisasikan pada populasi yang lebih besar. Pada penelitian ini menggunakan metode penelitian kuantitatif sehingga informasi yang didapat terbatas. Alat ukur yang digunakan menggunakan alat ukur self-presentation tidak terspesifik pada selfie, sehingga apabila ingin meneliti terkait selfie dapat menggunakan alat ukur selfie. Banyak faktor yang mempengaruhi ketidakpuasan tubuh, seperti terdapat faktor luar yang menghubungkan self-presentation dengan kepuasan tubuh seperti self-esteem. Selain itu saran praktis yang dapat diberikan adalah seperti orangtua dan pendidik. Saran yang dapat penulis berikan kepada orangtua yang memiliki anak yang masih remaja, untuk memantau serta membantu remaja dalam mencari identitas diri. Saran kepada pendidik seperti guru untuk mengambil peran dalam membantu siswa remaja di sekolah mengedukasi remaja terkait dampak positif dan negatif dari penggunaan media sosial. Mengedukasi siswa pentingnya menciptakan lingkungan pergaulan yang sehat, karena berkontribusi pada gangguan psikologis. Membantu siswa untuk mengasah kemampuan minat dan bakat yang dapat ditonjolkan remaja. Sehingga, remaja menjadi lebih percaya diri dan dapat menunjukkan eksistensi diri secara positif.

\section{Ucapan Terima Kasih (Acknowledgement)}

Terima kasih kami ucapkan kepada SMP X, Kepala Sekolah SMP X yang telah mengizinkan peneliti melakukan proses pengambilan data di SMP X. Terima kasih juga peneliti ucapkan kepada guru-guru SMP X yang turut membantu peneliti selama proses pengambilan data serta seluruh subjek penelitian yang telah berpartisipasi dalam penelitian ini.

\section{REFERENSI}

Albury, K. (2015). Selfies, sexts, and sneaky hats: Young people's understandings of gendered practices of self-representation. International Journal of Communication, 9, 1734-1745. https://ijoc.org/index.php/ijoc/article/view/3132/1396 
Ardari, C. S. S. (2016). Pengaruh kepercayaan diri terhadap intensitas penggunaan media sosial pada remaja awal. Skripsi. Tidak Diterbitkan. Fakultas Psikologi. Universitas Sanata Dharma: Yogyakarta. https://repository.usd.ac.id/6571/2/119114160_full.pdf

Aristantya, E. K., \& Helmi, A. F. (2019). Citra tubuh pada remaja pengguna instagram. Gadjah Mada Journal of Psychology, 5(2), 114-128. doi: 10.22146/gamajop.50624.

Charoensukmongkol, P. (2016). Exploring personal characteristics associated with selfie-liking. Cyberpsychology: Journal of Psychosocial Research on Cyberspace, 10(2), article 7. doi: 10.5817/CP2016-2-7.

Dohnt, H., \& Tiggemann, M. (2006). The contribution of peer and media influences to the development of body satisfaction and self-esteem in young girls: A prospective study. Developmental Psychology, 42(5), 929-936. DOI: 10.1037/0012-1649.42.5.929

Estiyani, R. (2018). Ekspresi diri melalui media sosial dan maknanya pada remaja SMP. Skripsi. Tidak Diterbitkan. Fakultas Psikologi. Universitas Muhammadiyah: Surakarta. https://core.ac.uk/download/pdf/159823165.pdf.

Fauziah, Y. R. (2019). Konsep diri remaja pengguna aplikasi Tik Tok di kota Bandung. Skripsi. Tidak Diterbitkan. Fakultas Ilmu Sosial dan Ilmu Politik. Universitas Komputer Indonesia: Bandung. https://elibrary.unikom.ac.id/id/eprint/2048/13/UNIKOM_Yuliani\%20Resti\%20Fauziah_ Jurnal.pdf

Fitriawati, D., \& Retnasary, M. (2018). Eksistensi diri youtuber Joneshood "studi fenomenologis mengenai eksistensi diri youtuber Joneshood di kota Bandung". Jurnal Signal Unswagati Cirebon, 6(1), 1-9. DOI: 10.33603/signal.v6i1.954

Frost, J. \& McKelvie, S. (2004). Self-esteem and body satisfaction in male and female elementary school, high school, and university students. Sex Roles, 51(1), 45-54. https://doi.org/10.1023/B:SERS.0000032308.90104.c6

Herring, S. C., \& Kapidzic, S. (2015). Teens, gender, and self-presentation in social media. In J. D. Wright (Eds.), International encyclopedia of social and behavioral sciences (2th ed.). Oxford: Elsevier. https://info.sice.indiana.edu/ herring/teens.gender.pdf

Koyuncu, M., Tok, S., Canpolat, A. M., \& Catikkas, F. (2010). Body image satisfaction and dissatisfaction, social physique anxiety, self-esteem, and body fat ratio in female exercisers and noexercisers. Social Behavior and Personality, 38(4), 561-570. https://doi.org/10.2224/sbp.2010.38.4.561

Lawler, M. \& Nixon, E. (2011). Body dissatisfaction among adolescent boys and girls: The effects of body mass, peer appearance culture and internalization of appearance ideals. Journal of Youth and Adolescence, 40(1), 59-71. doi: 10.1007/s10964-009-9500-2.

Lobo, S. S. \& Gowda, P. C. Y. (2016). The selfie phenomenon: Self-presentation and its implications. International Journal of Computational Research and Development, 1(1), 147-153. https://zenodo.org/record/220929\#.X-ck_S-cbOQ

Manago, A. M., Graham, M. B., Greenfield, P. M., Salimkhan, G. (2008). Self-presentation and gender on myspace. Journal of Applied Developmental Psychology, 29(6), 446-458. https://info.sice.indiana.edu/ herring/teens.gender.pdf

Martjin, C., Vanderlinden, M., Roefs, A., Huijding, J., \& Jansen, A. (2010). Increasing body satisfaction of body concerned women through evaluative conditioning using social stimuli. Health Psychology, 29(5), 514-520.

McCabe, M. P., Fuller-Tyszkiewicz, M., Mellor, D., Ricciardelli, L., Skouteris, H., \& Mussap, A. (2011). Body satisfaction among adolescents in eight different countries. Journal of Health Psychology, 17(5), 693-701. doi:10.1177/1359105311425274. 
McLean, S. A., Paxton, S. J., Wertheim, E. H., Masters, J. (2015). Photoshopping the selfie: Self photo editing and photo investment are associated with body dissatisfaction in adolescent girls. International Journal Eating Disorders, 48(8), 1132-1140. doi: 10.1002/eat.22449.

McLean, S. A., Jarman, H. K., \& Rodgers, R. F. (2019). How do "selfies" impact adolescents' well-being and body confidence? A narrative review. Psychology Research and Behavior Management, 12, 513-521. doi: 10.2147/PRBM.S177834

Meier, E. P., \& Gray, J. (2014). Facebook photo activity associated with body image disturbance in adolescent girls. Cyberpsychology, Behavior, and Social Networking, 4, 199-206. http://dx.doi.org/10.1089/cyber.2013.0305.

Merunkova, L., \& Slerka, J. (2019). Goffman's theory as a framework for analysis of selfpresentation on online social network. Masaryk University Journal of Law and Technology, 13(2), 243-276. doi: 10.5817/MUJLT2019-2-5

Mostafa, E. S. M., Eshak, E. S., Seedhom, A. E., \& Ghazawy, E. R. (2018). Media influence and body satisfaction among adolescent females, minia, Egypt. Journal of Public Health: From Theory to Practice, 26, 625-630. doi: https://doi.org/10.1007/s10389-018-0914-8

Myers, T. A., Ridolfi, D. R., Crowther, J. H., \& Ciesla, J. A. (2012). The impact of appearancefocused social comparisons on body image disturbance in the naturalistic environment: The roles of thin-ideal internalization and feminist beliefs. Body Image, 9, 342-351. doi: http://dx.doi.org/10.1016/j.bodyim.2012.03. 005

Ramadhan, R., Aminulloh, A., \& Yasak, E. M. (2017). Fenomena selfie (berfoto sendiri) di akun media sosial path sebagai bentuk ekspresi diri (pada remaja smk pgri 3 malang). Jurnal Ilmu Sosial dan Ilmu Politik, 6(1), 63-68. https://doi.org/10.33366/jisip.v6i1.373

Renfrew Center Foundation (2014, Februari 20) Afraid to be your selfie? Survey reveals most people Photoshop their images. The Renfrew Center. http://tinyurl.com/orsj9zc

Rieke, S. E., Fowler, D. C., Chang, H. J., \& Velikova, N. (2016). Exploration of factors influencing body image satisfaction and purchase intent: Millennial females. Journal of Fashion Marketing and Management, 20(2), 208- 229. doi: 10.1108/JFMM-12-20150094.

Rusdi, A. \& Lismayati, A. (2018). Analisis faktor eksploratori pada Skala Body Satisfaction Scale: Studi pada wanita remaja. Researchgate.net. doi: 10.13140/RG.2.2.20967.91048.

Song, H. K., \& Ashdown, S. P. (2013). Female apparel consumers' understanding of body size and shape: Relationship among body measurements, fit satisfaction, and body cathexis. Clothing and Textiles Research Journal, 31(3), 143-156. doi: 10.1177/0887302X13493127.

Worchel, S., Cooper, J., Goethals, G. R., \& Olson, J. M. (2000). Social psychology. Belmont, CA: Wadsworth

Zahroh, L. (2015). Urgensi pembinaan iklim dan budaya sekolah. Jurnal Pendidikan Agama Islam, 3(1), 157-186. http://jurnalpai.uinsby.ac.id/index.php/jurnalpai/article/view/43/42 